\title{
125 aniversario del Hospital Central de la Defensa «Gómez Ulla»"
}

\author{
Fernández-Tapia-Ruano M. ${ }^{1}$
}

Sanid. mil. 2021; 77 (1): 5-6, ISSN: 1887-8571

Hace 25 años, con la solemnidad y reconocimiento que se merecía celebramos la efeméride del primer centenario del hospital (1896-1996). De «nuestro hospital», cuya denominación hemos ido completando sucesivamente en función de las capacidades adquiridas, siendo hoy el Hospital Central Universitario de la Defensa. Y conservando el nombre del insigne Doctor D. Mariano Gómez Ulla. En este año 2021 y coincidiendo que celebramos su 125 aniversario, por Orden Ministerial 1/2001, añadimos a su denominación «Centro Sanitario de Vida y Esperanza».

Muchas, importantes y decisivas han sido las sucesivas transformaciones que ha marcado el desarrollo de nuestro hospital en estos últimos 25 años.

La profunda transformación que ha sufrido la organización y misiones de nuestras Fuerzas Armadas ha obligado al hospital a acompasar su evolución a la asunción y adquisición de nuevas capacidades y especializaciones para poder responder adecuadamente a lo demandado por dicha transformación.

En primer lugar, la supresión en Marzo de 2001 del Servicio Militar Obligatorio y la Profesionalización de la Tropa provocó que gran parte de la asistencia sanitaria fuese asumida por el ISFAS, lo cual disminuyó sensiblemente nuestra presión asistencial.

Asimismo, el aumento de la participación de nuestras Fuerzas Armadas en misiones internacionales obligó al hospital a llevar a cabo una gran transformación en su misión, pasando de ser de carácter mayoritariamente asistencial a fundamentalmente operativa, constituyéndose en verdadero Role 4 de apoyo a operaciones. Esta es su razón de ser primordial como Escalón Superior de Apoyo Sanitario a nuestras Fuerzas Armadas en dichas misiones.

Para seguir manteniendo la adecuada preparación de nuestros profesionales y asegurar además la capacidad asistencial, sin la cual no seríamos eficaces para cumplir nuestra misión operativa, a partir de 2007 se estableció un convenio con el Servicio Madrileño de Salud. En virtud de dicho convenio, este Hospital se incorporaba a su red sanitaria como Hospital de Nivel II, asumiendo la asistencia médica de una población aproximada de 100.000 habitantes de las Zonas básicas de Salud de Carabanchel y La Latina, convenio que se materializó y comenzó su andadura en 2011.

De esta forma, actualmente nuestro hospital desempeña su misión como Role 4, atendiendo a todo el personal evacuado desde Zona de Operaciones, para su estudio, tratamiento y valo-

${ }^{1}$ General de Brigada Médico. Director del Hospital Central de la Defensa «Gómez Ulla».Centro de Vida y Esperanza.mfertap@oc.mde.es.

Recibido: 8 de marzo de 2021

Aceptado: 17 de marzo de 2021

doi: 10.4321/S1887-85712021000100001 ración pericial. En concreto, durante el año 2020, se realizaron 101 evacuaciones sanitarias desde ZO sobre este Role 4.

Por otro lado, en virtud del mencionado convenio con el SERMAS, nuestra capacidad asistencial al personal civil ha ido en continuo aumento. Así, durante 2020 hemos atendido 55.000 urgencias, 9.048 hospitalizaciones y 353.153 consultas externas.

Es importante destacar también, que el hospital presta asistencia sanitaria a todo el personal de Fuerzas Armadas independientemente de su modalidad sanitaria que hayan escogido a través del ISFAS (Sanidad Militar, entidades privadas de seguro sanitario, etc.).

Además, se continúa realizando una actividad específica de este hospital militar, como es la labor pericial, para una mejor selección y recuperación de todo el personal de nuestras Fuerzas Armadas.

A todo ello sumamos una cada vez mayor actividad docente. Desde el año 2014, con la creación del CUD, se estableció un convenio con la Universidad de Alcalá de Henares para la enseñanza de pregrado de Medicina, Enfermería y Fisioterapia. En la actualidad más de 200 alumnos de medicina y 50 de enfermería, civiles y militares cursan sus estudios de pregrado en este hospital. A esto añadimos la formación especializada postgrado, con 26 especialidades acreditadas y 95 profesionales tanto civiles como militares llevando a cabo su residencia en nuestro hospital.

Respecto a la actividad en investigación, que junto con la asistencial y docente han sido siempre los ejes de esfuerzo del hospital, en estos momentos se están realizando 25 tesis doctorales, y últimamente se han publicado más de 150 artículos en revistas, junto con múltiples comunicaciones a congresos de todas las especialidades.

En resumen, una gran institución con más de 2.400 trabajadores civiles y militares entregados conjuntamente a la función operativa, asistencial, docente y pericial.

En el año 2020 la pandemia mundial que azotó con especial virulencia a nuestra región hizo que tuviéramos que poner en marcha la mayor operación asistencial a la que ha tenido que enfrentarse hasta ahora nuestro hospital. El inestimable apoyo del resto de las Fuerzas Armadas al hospital a través de la Operación Balmis, así como la total entrega y disponibilidad para el servicio de todo el personal de Sanidad Militar, en activo y reserva, hizo posible el éxito de esta gran operación con el menor número de bajas posible. Nunca habrá palabras que puedan expresar el agradecimiento a la labor incansable de entrega y profesionalidad a todo el personal del Hospital en plantilla y agregados, que actuaron como un gran equipo para hacer frente a semejante reto.

Hoy, calmadas en parte estas olas, y a la espera de las que puedan sacudirnos en el futuro, seguimos trabajando en nuestra misión con la misma ilusión, sabiendo que nuestros mayores ene- 


\section{EDITORIAL}

migos no son otros que la enfermedad y la muerte. Y a la lucha contra ellos dedicamos nuestro mayor esfuerzo diario.

Es un orgullo para mí dirigir esta Institución, buque insignia de la Sanidad Militar y formar parte de esta gran familia que son los hombres y mujeres de este Hospital. Queda mucho por hacer y mejorar, pero nunca nos dejaremos llevar por el desánimo y entre todos lograremos mejorar cada día nuestra misión fundamental, la atención a nuestros pacientes. 